\title{
La transferencia a hemodiálisis tras una peritonitis fúngica. ¿Es la opción definitiva?
}

\author{
Cristina Herrera Morales, Eva Barbero Narbona, Yaiza Martínez Delgado, Ernestina Junyent Iglesias \\ Servicio de Nefrología. Hospital del Mar. Parc de Salut Mar. Barcelona. España
}

\section{Introducción}

La peritonitis es una de las complicaciones más graves y frecuentes en los pacientes en tratamiento renal sustitutivo mediante diálisis peritoneal (DP), especialmente en la modalidad de diálisis peritoneal continua ambulatoria (DPCA) ${ }^{1}$.

La etiología bacteriana es la responsable de los episodios de peritonitis en el $80 \%$ de los casos, pero en cambio, la infección fúngica solo en el $4,6 \%$, aunque presenta peor pronóstico ya que se asocia con una alta morbi-mortalidad $^{2}$. Las guías de la Sociedad Española de Nefrología ${ }^{4}$ (SEN) recomiendan la retirada del catéter de forma inmediata, con la imposibilidad de continuar en el programa de DP.

Los agentes patógenos más habituales en la peritonitis bacteriana son: Staphylococcus coagulasa negativa y Staphylococcus aureus. En cambio, en la peritonitis fúngica, el patógeno habitual es la Candida albacans, aunque actualmente se ha observado mayor incidencia de Candida parapsilosis².

Los factores de riesgo más habituales son episodios previos de peritonitis bacteriana y el tratamiento con antibióticos de alto espectro ${ }^{1,2}$.

A continuación describiremos nuestra experiencia en un caso de peritonitis fúngica, cuya singularidad radica en su resolución; a pesar de la gravedad del caso y las complicaciones surgidas tras la trasferencia a Hemodiálisis (HD), la paciente pudo volver a DP.

Correspondencia:

Cristina Herrera Morales

Servicio de Nefrología. Hospital del Mar

Parc de Salut Mar

Passeig Maritim 25-29. 08003 Barcelona. España

E-mail: cherrera@parcdesalutmar.cat

\section{Caso clínico}

Los datos que se exponen en la descripción de este caso, se obtuvieron de los cursos clínicos de médicos y enfermeras de la paciente. Además, se solicitó consentimiento informado de la paciente.

\section{Descripción del caso:}

Mujer de 74 años con enfermedad renal crónica (ERC) estadio 5 atribuida a nefroangioesclerosis, con antecedentes de hipertensión arterial, hiperparatiroidismo secundario, síndrome anémico y leucemia linfática crónica tipo B, que eligió terapia sustitutiva de DP tras el proceso de toma de decisión.

Tiene 4 hijos pero vive acompañada de dos, cuida de los nietos, no sabe leer ni escribir, pero es independiente para las actividades diarias e instrumentales:

(Enero 2014) $\Rightarrow$ Barthel 100\%, Lawton-Brody 8/8, Calidad de vida (sf-12): PCS 50.6, MCS 59,7

EI 10/04/2013 se colocó catéter peritoneal e inició DPCA en domicilio el 22/5/2013, siendo la propia paciente la cuidadora principal.

El tratamiento de DPCA inicial fue de: 3 intercambios/ día (2 con Phisioneal $351,36 \%$ de glucosa y 1 con Extraneal, con volúmenes de $2000 \mathrm{ml}$ ). Diariamente ultrafiltraba $500 \mathrm{ml}$ con los intercambios y mantenía un volumen de diuresis de $1500 \mathrm{ml}$. El resultado del estudio de la membrana peritoneal antes de la ultima peritonitis mostró una membrana peritoneal HA (transportador medio alto).

En 8 meses presentó 4 episodios de peritonitis, de los cuales 3 fueron recidivante, con cultivo positivo de la misma bacteria (Staphylococcus epidermidis).

Se administró tratamiento antibiótico protocolizado: Vancomicina $1 \mathrm{gr} / 72 \mathrm{~h}$ intraperitoneal (IP) durante 15 
días y Fluconazol via oral (vo) durante 21 días. Tras la resolución de la ultima infección peritoneal se decidió realizar, además, sellados del catéter con Daptomicina (35 mg en 7,2 $\mathrm{ml}$ de ringer/24h después del último intercambio del día) medicación que se preparaba en el hospital, que la paciente recogía semanalmente y se auto administraba después del último intercambio del día en el domicilio.

\section{Episodio de peritonitis fúngica:}

Durante el periodo de sellado (14/8/2014) la paciente avisa al teléfono de urgencias, por líquido turbio, dolor abdominal y malestar general. Se realizó cultivo de líquido peritoneal protocolizado y quedó ingresada en espera de resultados. Tras el resultado del recuento celular, se inició tratamiento antibiótico empírico con Vancomicina lgr/72h y Ceftazidima 1gr/24h IP. El cultivo mostró crecimiento de BGN (Klebsiella oxytoca y Acinetobacter sp multisensible), por lo que se mantuvo tratamiento con Ceftazidima lgr/24h/IP, añadiéndose Gentamicina 40mgr/24h/IP y Ciprofloxacino 500 mg/12h vo.

Ante la mejoría clínica (efluente claro y sin problemas de drenaje) se decidió alta a domicilio. Se realizó reentrenamiento de la técnica y manejo de la medicación antibiótica domiciliaria (tratamiento IP durante 21 días).

A los ocho días, acude nuevamente a urgencias por líquido turbio, apareciendo en el cultivo un nuevo patógeno (Cándida parapsilosis) por lo que se añadió al tratamiento Fluconazol $200 \mathrm{mg}$ vo/24h, y quedó nuevamente ingresada.

Debido a la mala respuesta al tratamiento se decidió retirar el catéter Tenckoff, como recomienda el protocolo, y transferirla a Hemodiálisis definitivamente.

Se le coloco un catéter venoso bilumen (yugular derecho) provisional, en espera de programar intervención quirúrgica de fístula arterio-venosa interna en codo derecho (5/09/2014).

Cinco días después, se recambió el catéter venoso por disfunción y se visualizó mediante angio TAC, importante trombo en vena yugular por lo que precisó cirugía, ingreso en cuidados intensivos y colocación de un nuevo catéter (ubicación femoral). Este nuevo catéter, también, presentó trombosis venosa no oclusiva, por lo que precisó anticoagulación y retirada en 2-3 semanas.
A pesar de la utilización de la fistula arterio-venosa interna al mes de su intervención, se observó mala adaptación al tratamiento de HD por continuas hipotensiones, dificultad en la canalización venosa y dolor de la extremidad por síndrome de "robo".

La calidad de vida de la paciente había empeorado notablemente, tras el ingreso de $\mathbf{7 4}$ días y el traspaso a hemodiálisis:

(Octubre 2014) $\Rightarrow$ Barthel 95\%, Lawton-Brody 6/8, Calidad de vida (sf-12): PCS 20,1, MCS 40,3

Debido a las complicaciones, la mala adaptación a HD y por petición de la paciente, se replanteó volver a DP con el tratamiento de cicladora nocturna.

\section{Regreso a Dialisis Peritoneal:}

Así pues, el 19/12/14 se colocó catéter Tenckoff (vía laparoscopia para poder valorar las posibles adherencias, que pueden aparecer tras la peritonitis fúngicas) y como no hubieron problemas, en 1 mes la paciente reinició terapia domiciliaria de diálisis peritoneal automática (DPA). Como cuidador principal quedó la hija menor de la paciente, que aunque no vive con ella realizaba el montaje y conexión desplazándose al domicilio diariamente. La desconexión, solución de alarmas nocturnas y desmontaje de la maquina, lo realiza la paciente sin supervisión.

El tratamiento pautado con cicladora fue de: 8 horas, 4 ciclos de $2000 \mathrm{ml}$ (Phisioneal 35 1,36\%), 80 minutos de permanencia y día seco.

Diariamente tiene una ultrafiltrafiltración con el tratamiento de $400-500 \mathrm{ml}$ y mantiene un volumen de diuresis de $1500 \mathrm{ml}$. El test de equilibrio peritoneal se mantuvo igual que al inicio.

Actualmente lleva $>$ de 1 año sin ningún tipo de problema, recuperando prácticamente la autonomía y calidad de vida del inicio:

(Septiembre 2015) $\Rightarrow$ Barthel 100\%, Lawton-Brody 8/8, Calidad de vida (sf-12): PCS 43,6, MCS 51,5

Las guías SEN recomiendan realizar reentrenamiento después de cada episodio de peritonitis. El objetivo es buscar causas posibles, evaluar la capacitación 
del responsable y rectificar aquellos procedimientos erróneos. Esta metodología nos ayuda a revelar la posible causa de la infección. En nuestro caso, el resultado indicó que la paciente no había seguido las medidas de asepsia recomendadas en la manipulación del antibiótico para el sellado.

Con el primer resultado del cultivo del líquido peritoneal se diagnosticó la peritonitis bacteriana, pero acabo añadiendose, también, una peritonitis fúngica. Así pues, la infección fúngica condicionó la retirada del catéter peritoneal y el abandono del programa de diálisis peritoneal. El equipo multidisciplinar tomó la decisión de transferirla a HD definitivamente tras el diagnostico de peritonitis fúngica.

Muchos autores describen que la supervivencia de la técnica tras una peritonitis fúngica por Candidas no Albicans es muy baja, y además existen pocos pacientes que pueden retornar de nuevo a la terapia de DP tras el suceso, así lo describen García-Martos ${ }^{1,2}$ y Molina ${ }^{3}$ en sus estudios.

Las causas de que nos planteáramos que la paciente volviera a DP, fueron: la mala adaptación a la HD, las complicaciones surgidas durante el traspaso a hemodiálisis y la petición de la propia paciente. También se tuvo en cuenta la recomendación de las guías sobre la posibilidad de reinserción de un nuevo catéter peritoneal a las 4-6 semanas de la resolución del cuadro clínico.

Una vez tomada la decisión de regresar al programa de DP, estaba claro que era necesario un cambio de estrategia, de manera que se propuso iniciar en forma de cicladora automática, con la finalidad de disminuir el número de manipulaciones del paciente/familia con el catéter. Pero también, era imprescindible evitar nuevos episodios de infección, por eso, se pensó en buscar un nuevo responsable para realizar la técnica y todo ello nos condujo a reiniciar el proceso de entrenamiento con la hija y puesta en marcha de la técnica en casa.

\section{Conclusiones}

El esfuerzo en adaptar los tratamientos a las necesidades de los pacientes es una rutina en las Unidades de Diálisis Peritoneal, el buscar soluciones consensuadas con el paciente/familia, tomar decisiones teniendo en cuenta su opinión y circunstancias, requiere empeño, imaginación y conocimientos, por un lado sobre recursos de la familia/comunidad/sistema y por otro los propios de la especialidad.

En este caso, la paciente lleva más de 1 año en DP modalidad automática, no ha presentado ningún episodio de peritonitis, ha recuperado autonomía y la percepción de calidad de vida ha mejorado recuperando los niveles previos.

A pesar de los episodios de peritonitis, el transporte peritoneal no quedó alterado, de manera que en la actualidad se alcanza una diálisis adecuada, manteniendo aclaramiento y ultrafiltración. Por lo que, podemos afirmar que el traspaso de responsabilidades resultó efectivo en el control de complicaciones derivadas de la técnica, y en cuanto a los recursos utilizados, se precisó implicar a un nuevo cuidador. De momento, la cuidadora no refiere tener sobrecarga, pero no obstante seguimos el caso de cerca.

Recibido: 1 septiembre 2016

Revisado: 15 septiembre 2016

Modificado: 30 octubre 2016

Aceptado: 15 noviembre 2016

\section{Bibliografía}

1. García-Martos P, Gil F, Marín P, García-Agudo $L$, García-Agudo R, Tejuca F, et al. Peritonitis fúngica en diálisis peritoneal continua ambulatoria: descripción de 10 casos. Nefrol. 2009; 29(6):534-539.

2. García-Agudo R, García-Martos P. Aspectos clínicos y bacteriológicos de la peritonitis fúngica en diálisis peritoneal. Nefrol. 2009; 29(6):506-517.

3. Molina $P$, Puchades MJ, Aparicio M, García Ramón $R$, Miguel $A$. Experiencia en peritonitis fúngica en una unidad de diálisis durante diez años. Nefrol. 2005; 25:393-398.

4. Sociedad Española de Nefrología (S.E.N). [acceso 7 noviembre 2016]. Disponible en: http://www. senefro.org/modules/webstructure/files/guas_de_ dilisis_peritoneal.pdf?check_idfile $=1173$. 